\title{
Teatro e Comunidade: dialogando com Brecht e Paulo Freire
}

\author{
Marcia Pompeo Nogueira
}

Na busca de instrumentos metodológicos que pudessem guiar nossa prática de Teatro para o Desenvolvimento de Comunidades, investigamos dois autores Bertolt Brecht e Paulo Freire.

Num tempo em que as propostas artísticas de Brecht são incorporadas muitas vezes fora do seu contex to ${ }^{2}$, em que o efeito de distanciamento faz parte do repertório da publicidade ${ }^{3}$, o importante não é reproduzir o que Brecht fez, mas buscar o sentido de suas propostas numa prática que mantenha a perspectiva transformadora da arte. É neste sentido que estamos propondo uma aproximação entre Brecht e o Teatro para o Desenvolvimento de Comunidades. Nosso trabalho não busca a montagem de textos escritos por Brecht, ele nos inspira na criação de performances ligadas à realidade concreta das comunidades com quem trabalhamos.

A aproximação com Paulo Freire já é mais fácil de ser vista, já que ele fundamenta a versão dialógica do teatro do desenvolvimento. Construída principalmente na África durante o período próximo às lutas de independência, o modelo imposto de desenvolvimento - que partia da concepção: "Nós sabemos o que é bom para vocês" - cedeu muitas vezes lugar para uma prática em que o teatro contribuía para a identificação e elaboração dos problemas junto às e pelas comunidades. Inspirados por Freire, processos baseados no diálogo, na troca de conhecimento, na construção de uma perspectiva crítica de aspectos concretos da realidade vivida pelas pessoas dessas comunidades, tiveram espaço de elaboração, gerando as bases para uma praxis política de construção de um mundo melhor.

IProfessora da Universidade do Estado de Santa Catarina, atua na linha de pesquisa Pedagogia do Teatro, com pesquisa na área do Teatro para o Desenvolvimento de Comunidades. Fez mestrado na ECA/ USP e Doutorado na Universidade de Exeter, Inglaterra.

${ }^{2}$ Esta referência abrange por exemplo o livro Postmodern Brecht de Elizabeth Wright.

${ }^{3}$ Costa, Iná in Jameson, F. O Método Brecht. Rio: Vozes, 1999.

\footnotetext{
Dezembro 2007 - № 9 Teatro e Comunidade: dialogando com Brecht e Paulo Freire. Marcia Pompeo.
}

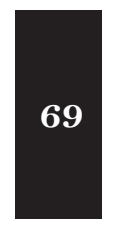


A relação entre esses dois autores nos pareceu interessante de investigar tanto em termos teóricos como práticos. Dois processos de criação teatral, um envolvendo a comunidade de Ratones e outro a comunidade Nova Esperança, foram nossos campos de experimentação das possibilidades indicadas por estes dois autores e principalmente sobre dois conceitos propostos por eles: o verfremgdun effect (efeito-V) proposto por Brecht, às vezes traduzido por distanciamento; e o conceito de codificação proposto por Paulo Freire.

\section{As relações entre Bertolt Brecht e Paulo Freire}

O foco de Brecht era o teatro, o de Freire a educação, mas apesar desta diferença inicial, a aproximação entre eles revelou uma identidade surpreendente.

Ambos dirigem seu trabalho para aqueles que podem transformar o mundo.

Brecht queria associar seu teatro aos que "necessariamente estão impacientes para efetuar grandes modificações” (BRECHT, 1967: 191). Queria deslocar seu teatro para "os subúrbios da cidade, onde ficará à disposição das vastas massas que produzem em larga escala e que vivem com dificuldade (...)"(BRECHT, 1967: 191).

Seu teatro experimental atuou desde cedo para além do teatro profissional. Em conjunto com seus artistas, durante a república Weimar, na Alemanha, participou de experiências teatrais nas escolas, trabalhou com corais operários, com amadores, práticas que influenciaram sua experiência estética.

Freire dirige sua pedagogia ao oprimido, "aos esfarrapados do mundo e aos que neles se descobrem e, assim descobrindo-se com eles sofrem, mas, sobretudo, com eles lutam" (FREIRE, 1977: 17).

Ambos acreditam na transformação do homem, encaram-no como ser fazedor de história:

Para Brecht, as condições históricas não devem ser imaginadas ou construídas como poderes misteriosos; "pelo contrário, elas são criadas e mantidas pelos homens (e serão, quando for o caso, modificadas por eles)" (BRECHT, 1967: 198). 
Para Freire, o que distingue os homens dos animais é a capacidade dos primeiros de criar o domínio da cultura e da história: A través de sua permanente ação transformadora da realidade objetiva, os homens simultaneamente, criam a história e se fazem seres histórico-sociais (FREIRE, 1977: 108).

Ambos assumiram posições de esquerda, sem, contudo, limitarem-se a uma cartilha ortodoxa:

Freire expressa claramente sua discordância à proposta de Lukács de “explicar às massas sua própria ação" (FREIRE, 1977: 42), sua perspectiva é de "dialogar com elas sua ação" (FREIRE, 1977: 42). A propaganda, o dirigismo, a manipulação, como armas de dominação, não podem ser instrumentos para esta reconstrução (FREIRE, 1977: 60).

Brecht, da mesma forma, diferencia seu teatro da postura "panfletária" assumida por Piscator, com quem colaborou, seu método já não buscava convencer as pessoas de determinadas posições: "Quero dizer que quanto mais levávamos o público a "marchar", a comungar, a se identificar, menos ele via o encadeamento de causas e efeitos, menos ele aprendia (...)" (BRECHT, 1967: 131).

Seu objetivo não era de convencer as pessoas de determinadas posições. Queria deixá-las livres para pensar.

Ambos partiam do concreto para o abstrato, explorando as contradições:

As peças de Brecht apresentavam fragmentos de realidades, que ele chamava de "modelos de relações entre os homens" (BRECHT, 1967: 132), apresentados muitas vezes dentro de sua falta de clareza, enquanto uma alternativa histórica, fruto das opções humanas, explicitando suas contradições:

Brecht, por sua vez, pretende inicialmente nos mostrar a relação entre os homens, entre um homem e a História - não nos expor toda esta História. Para ele, há, de um lado, a vida individual deste homem e, de outro, a História: cabe ao espectador efetuar o vaivém entre os dois e extrair dai a moral, a sua moral (DORT, 1977: 286-287).

Da mesma forma, Freire também propõe, no seu processo educacional, que se parta de situações existenciais concretas. 
Esta prática implica, por isto mesmo, em que o acercamento das classes populares se faça, não para levar-lhes uma mensagem "salvadora", em forma de conteúdo a ser depositado, mas, para, em diálogo com elas, conhecer, não só a objetividade em que estão, mas a consciência que tenham desta objetividade; os vários niveis de percepção de si mesmos e do mundo em que e com que estão (FREIRE, 1977: 101).

Neste sentido, Freire é mais radical do que Brecht. Para ele não basta trabalhar com "modelo de realidade", ele propõe um método de real aproximação com a comunidade que se pretende trabalhar. Educador e educando se transformam em pesquisadores que visam à identificação de temas geradores, universo vocabular e situações limite características de uma comunidade específica.

Para concretizar este paralelo, sem nos perdermos no imenso material bibliográfico produzido por e sobre estes autores, vamos nos concentrar em dois conceitos: o verfremgdun effect (efeito-V) proposto por Brecht, às vezes traduzido por estranhamento outras por desfamiliarização, ou ainda por distanciamento; e o conceito de codificação proposto por Paulo Freire.

\section{O conceito de codificação}

Como parte da educação conscientizadora freireana, existe um instrumento central proposto para desvelar a realidade, parte do processo de transformar a realidade, o conceito de codificação.

Para Freire, a realidade concreta não pode ser reduzida a fatos observáveis; ela também inclui a forma como a as pessoas a percebem. Subjetividade tem que se unir com objetividade para gerar uma percepção acurada da realidade. Codificação representa uma forma de focar o diálogo - entre os facilitadores e os membros da comunidade envolvidos no projeto objetivando desvelar a realidade, o que inclui aspectos objetivos e subjetivos. Codificação é feita de situações de vida.

A codificação representa uma dada dimensão da realidade da forma como é vivida pelo povo, esta dimensão é proposta para ser analisada num contexto diferente do que o que ela é vivida. Neste sentido, a codificação transforma o que era uma forma de vida num contexto real, num 'objeto' no contexto teórico (FREIRE, 1982: 32). 
Codificação permite aos participantes uma percepção distanciada de sua vida quotidiana, que pode ser admirada, isto é, observada a distância, transformada em um objeto que pode ser coletivamente analisado. A codificação funciona como uma ponte entre os contextos teórico e prático. Uma imagem da realidade concreta é um ponto de partida para uma análise abstrata que pode desvelar profundos relacionamentos dos atores sociais que passam freqüentemente despercebidos. Para Freire, isto faz parte de um processo contínuo de conhecimento onde não se tenta apenas entender a realidade, mas também a percepção anterior que se tinha dela. Freire apresenta em Pedagogia do Oprimido, um exemplo de codificação proposta enquanto parte de uma investigação temática em Santiago do Chile. Uma imagem mostrava um homem embriagado andando na rua e três jovens conversando numa esquina. Esta foto havia sido proposta para discutir o problema de alcoolismo. Para surpresa do facilitador, os comentários dos educandos foram:

Aíapenaséprodutivo eútil à naçãoo "borracho" que vem voltando para casa, depois do trabalho, em que ganha pouco, preocupado com a família, a cujas necessidades não pode atender. É o único trabalhador. É um trabalhador decente como nós, que também somos "borrachos" (FREIRE, 1977: 133).

Se perguntados diretamente, os participantes poderiam ter afirmado que nunca tinham se embriagado na vida. $\mathrm{O}$ educador poderia ter assumido uma postura crítica em relação ao álcool sem, entretanto, levantar uma discussão interessante. Através da codificação o problema de baixos salários, do sentimento de ser incapaz de sustentar a família foram levantados. Ao mesmo tempo, os educandos se reconheceram como "trabalhadores decentes". No lugar de uma discussão moralista, a codificação permitiu que o grupo focasse nas causas do problema.

A identificação da realidade dos participantes é apenas o começo do trabalho. Freire cita Chomsky em relação ao que se espera da análise da codificação. Ele fala que a "leitura" da codificação deve incluir o que Chomsky chama de "estruturas de superfície" e as "estruturas profundas" (FREIRE, 1982: 51). O primeiro nível inclui a descrição da codificação, identificando seus elementos constitutivos, que devem ser seguidos de uma exploração mais profunda. Muitos problemas podem ser discutidos a partir de uma codificação.

O processo de descodificação requer que se mova da parte ao todo e que retorne para a parte; do concreto ao abstrato e ao concreto novamente, parte de um constante fluxo e re-fluxo. A través desse processo é possível que se 
atinja uma perspectiva crítica da realidade concreta, anteriormente percebida como densa e impenetrável (FREIRE, 1977: 114).

A escolha de uma boa codificação é fundamental para o desenvolvimento de uma análise crítica frutífera. Freire apresenta as seguintes condições:

Uma primeira condição a ser cumprida é que, necessariamente, devem representar situações conhecidas pelos indivíduos cuja temática se busca, o que as faz reconhecíveis por eles. [...] Igualmente fundamental para sua preparação é a condição de não poderem ter as codificações, de um lado, seu núcleo temático demasiado explícito; de outro, demasiado enigmático. [...] Na medida em que representam situações existenciais, as codificações devem ser simples na sua complexidade e oferecer oportunidades plurais de análise na sua descodificação, o que evita o dirigismo massificador da codificação propagandística. As codificações não são slogans, são objetos cognoscíveis, desafios sobre o que deve incidir a reflexão crítica dos sujeitos descodificadores (ibid: 127-128).

\section{O Conceito de Distanciamento}

De forma semelhante à codificação freireana, o estranhamento brechtiano permite que se reconheça um objeto e que este ao mesmo tempo lhe pareça estranho.

A origem do termo em alemão Verfremdungeffect vem de uma oposição ao termo entfremdung, que significa alienação. O que Brecht busca, ao propor este conceito é, portanto, empreender um processo de “desalienação", necessária enquanto uma condição para seu teatro realizar reproduções eficazes da realidade.

A finalidade do efeito- $V$ estaria ligada a um questionamento da realidade através do teatro. A arte teria que assumir o compromisso da urgente transformação da sociedade. Brecht entendia que:

As relações entre os homens, com efeito, tornaram-se mais impermeáveis do que outrora. A enorme tarefa em que estão empenhados parece cada vez mais dividi-los em dois grupos; aumento de produção causa aumento de miséria; somente uma minoria lucra com a exploração da natureza, e, precisamente por estarem a explorar homens (BRECHT, 1967: 189-190). 
Uma das causas dos problemas permanecerem insolúveis estaria, para ele, ligada à familiaridade com que se revestiam os problemas sociais, ela fazia com que não se percebesse a sociedade como possível de ser modificada: “quem desconfia de algo a que está acostumado?” (BRECHT, 1967: 201). Para reverter esta situação Brecht propõe a utilização do efeito-V.

Para transformá-lo [o público] de uma aceitação passiva para um estado correspondente de curiosidade e dúvida é necessário que ele desenvolva um olhar de estranheza (...) [O teatro] tem que surpreender seu público, e chegar a isso por uma técnica que torne o familiar estranho (BRECHT, 1967: 201).

Mas o que é este efeito de distanciamento? Brecht deixa claro que se trata da utilização de uma técnica artística antiga, presente tanto na comédia clássica, em certos ramos da arte popular, como das práticas do teatro asiático (BRECHT, 2002: 98). Esta nova forma de o propor aparece com objetivos claros de proporcionar uma perspectiva crítica através de uma forma artística que teria a função de tornar o que é habitual em algo estranho.

O sentido do efeito-V envolve, para Brecht, diferentes dimensões. Pode assumir, entre outros, um sentido ligado à vida diária. Alguma coisa que nos pareça óbvia é transformada, de alguma maneira, em algo incompreensível. Desta forma se pretende descobrir um novo significado em coisas do nosso cotidiano.

Um efeito de distanciamento, dos mais simples, é usado quando uma reunião de negócios se inicia com a sentença: os senhores já pensaram no que acontece com os resíduos que são despejados noite e dia da fábrica para o rio? Estes resíduos não são levados pelo rio por acaso, eles foram cuidadosamente canalizados para lá, pessoas e máquinas foram utilizadas para fazer isto, o rio fica completamente verde, todos sabiam que os resíduos eram levados pelo rio, mas simplesmente como resíduos. Ele era o resto imprestável da fabricação, mas agora ele se torna objeto de interesse. A pergunta distanciou os resíduos e esta era a intenção dela (BRECHT, 1967: 174).

${ }^{4}$ Escrito em 1936/1937 provocado por um espetáculo do ator chinês Mei

Um outro exemplo interessante é apresentado por Brecht no texto "O Efeito de Distanciamento nos Atores Chineses" 4 para diferenciar o processo de ensaio no teatro Brechtiano. Um incidente insignificante, um mero começo de Lan-fang, que Brecht assistiu em Moscou em 1935.

Dezembro 2007 - № 9 Teatro e Comunidade: dialogando com Brecht e Paulo Freire. Marcia Pompeo. 
uma história: "uma moça deixa sua casa para se empregar numa cidade grande", poderia ser estranhado por um ator que quisesse mostrar este incidente como único, como histórico, que possa conduzir a reflexões sobre a estrutura da sociedade em que este "fato corriqueiro" se dá:

Em certo sentido, o incidente é universal: as moças se empregam (no caso em questão, fica-se interessado em ver o que particularmente vai acontecer com ela). Só uma coisa o particulariza: a moça vai embora (se ela tivesse ficado o que vem depois não aconteceria). O fato de que sua família a deixa ir não é objeto de indagação. É compreensivel (os motivos são compreensiveis). No teatro historicizante, tudo é diferente. Concentra-se no fato de que todos os acontecimentos cotidianos são significativos, particulares, merecedores de indagação. O quê! Uma família deixando um de seus membros abandonar o ninho para ganhar a vida, independente e sem ajuda? Ela será capaz disso? $O$ que aprendeu aqui como um membro da família, a ajudará a ganhar a vida? As famílias ainda são capazes de manter seus filhos presos? Tornaram-se (ou continuam sendo) uma carga? Isso acontece com todas as famílias? Sempre foi assim? É assim que as coisas são? Podem ser mudadas? A fruta madura sempre cai da árvore? - essa frase pode ser aplicada aqui? As crianças sempre se tornam independentes? Faziam o mesmo em outros tempos? Se sempre fizeram, por um fator biológico, foi sempre da mesma maneira, pelas mesmas razões e com os mesmos resultados? (BRECHT, 1967: 112-113).

Esta característica historicizante e questionadora do efeito de distanciamento abrem caminho para uma nova estética. Para se atingir o distanciamento, não se buscará mais fingir que existe uma quarta parede separando o ator do público, os refletores ficam a mostra, não se precisa mais criar a ilusão de que se está em um determinado lugar. Os atores não precisam fingir que se trata de uma representação natural, não ensaiada. Sua representação deve fugir de processos de identificação com o personagem, da necessidade de "hipnotizar" o público e de levá-lo a um "transe emocional". Para manter o espírito crítico do espectador de teatro, semelhante à atitude do público de uma luta de box, deve-se criar um envolvimento que permita a presença constante do espírito crítico sobre o que acontece no palco.

$\mathrm{O}$ efeito- $\mathrm{V}$ adquiriu diferentes formatos na prática teatral de Brecht, abrangendo desde a interpretação do ator - que deve mostrar seu personagem, sem se confundir com ele; o cenário e a música, que se posicionam sobre o que acontece no palco; recursos como tabuletas com o título das cenas, anunciando 
a ação, seu local e momento. Estes recursos não devem, entretanto, ser entendidos como técnicas independentes do sentido que se quer atingir, nem como as únicas formas possíveis para se concretizar o efeito de estranheza desejado.

\section{Codificação e Distanciamento no Teatro em Comunidades}

A semelhança entre os dois autores salta aos olhos e o paralelo entre os dois conceitos reforça esta percepção: ambos buscam uma maior compreensão e engajamento crítico com vistas à transformação da realidade através de um exercício de distância sobre elementos da realidade. Por outro lado, a análise destes conceitos nos permite também identificar uma complementaridade entre eles: se Freire nos fundamenta numa necessidade de envolvimento com a realidade vivida por uma determinada comunidade, Brecht nos alimenta com alternativas concretas para o trabalho teatral.

Seriam, entretanto, as contribuições teatrais de Brecht, como o uso da representação distanciada, acessível apenas para profissionais especializados? Sabemos que Brecht também se envolveu com alunos em escolas, com corais operários e com teatro amador. Como o efeito-V seria usado neste contexto? Algumas referências importantes para responder a esta questão estão no Diário de Trabalho de Brecht 1938-1941 (BRECHT, 2002). Nesta obra ele se expressa sua vontade de escrever uma peça para ser representada por crianças. Entre as vantagens de sua interpretação ele destaca:

A experiência mostra seguidamente (penso, por exemplo, na produção de Um Homem é um Homem, pelos alunos do ginásio de Neukölln) que as crianças são muito boas em compreender aquilo que de algum modo vale a pena compreender, precisamente como os adultos. $E$ as coisas que valem a pena para elas são as mesmas. Os processos internos da alma, nuances de atmosfera, tragédias etc., elas não querem saber disso (BRECHT, 2002, p. 152).

Num outro momento desse mesmo diário, Brecht comenta uma apresentação de um pequeno esquete por crianças. No fim, os atores infantis cantam uma canção ao público. Brecht comenta:

Interessante efeito- $d^{5}$. Impessoalidade na elocução e nos gestos (não se viam expressões faciais controladas), o modo como ficam a vontade quando não é a vez delas. O vigor com que vão a diante.(...) (BRECHT, 2002: 154).

${ }^{5}$ Nesta tradução do livro Brecht, B. Diário de Trabalho 1936-194. Rio de Janeiro: Rocco, 2002, 0 efeito de distanciamento é designado por efeito-d. 


\section{Urdimento}

${ }^{6}$ Projeto de Extensão "Teatro com Crianças e Adolescentes", coordenado por Márcia Pompeo Nogueira.

${ }^{7}$ Período em que a coordenadora se afastou para doutorado na Inglaterra.

${ }^{8}$ Os novos coordenadores contaram com a supervisão semanal de Márcia Pompeo Nogueira e com 0 apoio de oficinas intensivas - um final de semana inteiro no Centro e Artes da UDESC em que o grupo participa de oficinas teatrais diversas, ministradas por estagiários do curso de Artes Cênicas CEART/UDESC.
Por esses comentários podemos perceber como, no trabalho com jovens e crianças, o efeito- $\mathrm{V}$ deixa de ser uma técnica difícil de ser atingida, para ser um modelo de representação mais adequado aos limites e possibilidades dessa faixa etária. Aqui não há a obrigatoriedade de hipnotizar a platéia com representações arrebatadoras. Quando se permite às crianças outro tipo de representação os resultados são mais satisfatório. Por outro lado, suas limitações revelam-se como qualidades que contribuem para a expressão dentro desta proposta estética.

Influenciada por esses dois conceitos me envolvi em dois trabalhos em comunidades do Sul do Brasil. O primeiro em Ratones, apoiada por duas pessoas da comunidade que coordenavam os trabalhos, Natanael Ireno Machado e Rafael Buss Ferreira. O segundo em Nova Esperança, apoiada por duas estudantes do Centro de Artes da UDESC, Maria Amélia Gimmler Netto e Paula Carina Kornatski.

Não vou poder entrar em muitos detalhes sobre essas práticas no curto espaço deste artigo, mas poderei apresentar resumidamente elementos dos processos de criação que metodologicamente foram guiados pelos dois autores estudados.

\section{“Deu até Briga no 604”: uma experiência teatral em Ratones}

Ratones tem sediado um projeto de teatro ${ }^{6}$ desde 1991. Interrompido por quatro anos a partir de $1999^{7}$, e retomado em 2002 com o processo que gerou o espetáculo "Deu até Briga no 604". Antigos participantes hoje são os coordenadores do trabalho ${ }^{8}$.

O processo criativo deste espetáculo partiu de uma codificação que identificamos como significativa para a comunidade. Dialogando com os novos coordenadores escolhemos como ponto de partida para o trabalho teatral uma briga que aconteceu no ônibus de Ratones entre o "pessoal de cima" e o "pessoal de baixo". A briga entre estes dois grupos é antiga na comunidade e este incidente no ônibus revelava um momento crítico da escalada de violência na relação entre os dois grupos.

Uma discussão inicial com os coordenadores do teatro, em Ratones, explicitou uma importante contradição. Apesar da briga ser entre o "pessoal de cima" e o "pessoal de baixo", como o caminho de Ratones é sinuoso, com muitos altos e baixos, não existe clareza para seus habitantes sobre quem mora em cima e quem mora em baixo. 
No processo de criação partimos de uma improvisação da briga no ônibus, seguida da criação, em pequenos grupos, de momentos reais ou imaginários que justificassem esta briga, que a explicassem de alguma forma. Estas improvisações representavam instâncias de análise da codificação proposta.

As cenas criadas incluíam uma briga imaginada, que poderia ter acontecido durante um passeio escolar, entre as crianças que não tinham lanche para comer, e as que trouxeram bastante lanche e queriam comê-lo sozinhos. Outras cenas foram sobre brigas em festas da comunidade e brigas a partir de jogo de futebol.

Através destas cenas outros problemas da comunidade se explicitaram: a rivalidade entre "os de dentro" - antigos moradores da comunidade - e "os de fora" - novos moradores de Ratones. A cena da festa se transformou numa nova codificação. Os antigos moradores de Ratones construíram um salão próximo à igreja católica da comunidade. No entanto, os "de fora", ligados à igreja, estavam administrando o salão e excluíam os "de dentro" quando organizavam as festas da comunidade, em função da imposição de outros padrões culturais dos que ali eram tradicionais.

Todas essas contradições foram apresentadas para a comunidade, que lotou o salão da igreja. O espetáculo se estruturou da seguinte forma: no início foi apresentada a codificação, isto é, a cena da briga do ônibus, da forma como realmente aconteceu. Ao final desta cena, um narrador questionou os moradores sobre o problema apresentado e instigou a platéia perguntando quem era "de baixo" e quem era "de cima". Conhecedor das pessoas que ali estavam, explicitou a contradição questionando duas moradoras vizinhas que se manifestaram uma como moradora "de cima" e a outra como moradora "de baixo”. Esta evidência causou um burburinho na platéia. Retomado o espetáculo, foram apresentadas as cenas do passeio escolar, das brigas nas festas e no jogo de futebol, aumentando o clima de rivalidade entre os dois grupos. No final, a cena da briga no ônibus é repetida e interrompida antes de seu final pelo narrador, que questiona a comunidade sobre as consequiências deste problema.

A comunidade se identificou com o que foi mostrado no espetáculo, mas a curto prazo, pelo menos, a resposta em relação à rivalidade entre "os de dentro" e "os de fora" nos surpreendeu. Os administradores do salão da igreja, que não gostaram de ver suas atitudes espelhadas no palco, proibiu o grupo de ali se apresentar novamente. Por outro lado, a comunidade se reconheceu nos problemas apresentados entre "os de cima" e "os de baixo". 


\section{Urdimento}

${ }^{9} 0$ Boi de Mamão é uma manifestação cultural popular em Santa Catarina. Este era um projeto de estágio curricular coordenado por Débora Matos e Rudmar da Silva Marcos, sob a supervisão de Marcia Pompeo Nogueira. Contou também com a colaboração de Nado Gonçalves. Incluiu diferentes grupos da comunidade, incluindo crianças, jovens e adultos. Culminou numa apresentação prestigiada por toda a comunidade.

${ }^{10} 0$ projeto "Entrelaços do Saber", do Centro de Educação da FAED/UDESC, coordenado por Nadir Esperança Agideiro e Ivone Perassa.

\footnotetext{
${ }^{11}$ Termo usado pelos integrantes do grupo para definir quem vende pequenas quantidades de maconha.
}

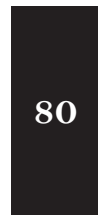

Trouxeram novos detalhes da origem desse conflito. Pessoas do grupo que brigou no ônibus acharam que a essência do problema estava retratada no espetáculo. Um depoimento de um deles nos alertou: o próximo passo poderia ser um assassinato. Talvez este espetáculo tenha contribuído para todos na comunidade refletirem de forma distanciada e crítica sobre o problema, de maneira que esta escalada de violência pudesse ser controlada. Soubemos que os debates continuaram entre os moradores, que puderam explicitar e refletir sobre seus pontos de vista.

\section{"Vidas Lokas"}

Nossa aproximação com a comunidade Nova Esperança teve início em 2003. Visitamos as pessoas em suas casas, tentado esclarecer nossa proposta de teatro. Desenvolvemos um projeto teatral ligado ao "Boi de Mamão", envolvendo diversos segmentos da comunidade, sempre trabalhando de forma integrada com outros projetos em andamento na comunidade ${ }^{10}$.

"Vidas Lokas" foi um espetáculo feito com um grupo de jovens de Nova Esperança em 2004. O grupo de adolescentes foi se familiarizando com a linguagem teatral, através de jogos, trabalhos com imagens e improvisações. Neste processo construíam as cenas que chamamos de "fragmentos de realidade" ou codificações. Os personagem centrais de "Vida Loka" eram Kelly e Romário - típicos adolescentes da periferia de Florianópolis. Escolhemos três cenas para focar o processo criativo: "A filha rebelde" que retratava a situação familiar de Kelly, sua relação difícil com a mãe; "A fuga" cena onde Kelly, ao saber que estava grávida, conta ao namorado Romário, que foge para não assumir o filho; "A cobrança" que representa a relação da juventude com o tráfico de drogas, culminando com a morte de uma "casqueira" ${ }^{11}$ por um traficante.

As situações eram propostas e aprofundadas, pelos jovens, através dos jogos teatrais. Nossas tentativas de debate fora do contexto do jogo, eram pobres. Os argumentos eram superficiais, não havia interesse. Era através do teatro que o debate sobre as cenas, e sua relação com a realidade, aconteciam. O tema de "A Cobrança", por exemplo, era profundamente relacionado com a realidade de Nova Esperança. Os moradores têm que sobreviver ao uso e à comercialização da droga por algumas pessoas de dentro ou de fora da comunidade, bem como às constantes batidas da polícia. Entender os personagens propostos pelo grupo e o relacionamento entre eles era uma forma de aprofundar o entendimento do problema.

Trabalhando com este tema delicado, entendemos que precisávamos ter cuidados especiais na abordagem desta cena. Estimular estes jovens a fingir que consumiam drogas, mesmo trabalhando com drogas imaginárias, 
nos pareceu inadequado. Propusemos então a busca de uma simbologia para a cena. Várias alternativas foram experimentadas: representá-la por um chocolate, uma flor, etc. O grupo escolheu um pirulito. A proposta era dar realidade ao pirulito, deixando claro que este representava uma droga que os viciava. Esta forma de se abordar o uso de drogas de forma simbólica e lúdica era, na verdade, uma forma distanciada de encarar o tema.

Um jogo fundamental foi " A berlinda". Os jovens respondiam, enquanto personagens, às perguntas dos facilitadores e de todo o grupo, sempre usando a primeira pessoa. Foi através desse jogo que muitos se apropriaram de seus personagens, ganhando concentração e seriedade e reflexão crítica sobre a realidade. João (nome fictício), que fazia o traficante, refletiu sobre as opções de vida desse personagem, através da cena. Sua relação com a polícia e com os outros traficantes, seu dinheiro fácil e sua vida sem futuro. Os conteúdos traziam seriedade para o trabalho cênico e o trabalho cênico levava a uma reflexão sobre a realidade.

Seguindo o modelo proposto por Brecht para historicizar um acontecimento e transformar uma história corriqueira em algo extraordinário, fizemos perguntas aos personagens de cada uma dessas cenas. Nosso objetivo era investigar: as coisas sempre foram assim? Sempre pelas mesmas razões? Buscando os mesmos resultados? É o homem que faz a história? O que pode ser mudado?

Sobre a cena "A cobrança", perguntamos: Quem vende a droga lucra com ela? Por que existem as "casqueiras"? Elas existem em toda parte? Quem se dá bem com as drogas? Por quanto tempo? Quem mais sofre com a droga? Kelly sabia que as drogas viciam? Ela sabia que teria que pagar pela droga? Por que comprava se não tinha dinheiro? Kelly vendia droga pra quem não podia pagar? Ela sabia o que a droga poderia fazer para as pessoas que compravam? O chefão sabia? Seu "braço direito" sabia? O "braço direito" pagava a droga que consumia? Ele também podia morrer se não pagasse? Sempre se mata quem deve?

Os questionamentos aprofundavam os personagens que se comprometiam pelas opções que assumiam. As cenas ganhavam mais ação, aumentava a cumplicidade entre os personagens.

Sobre a cena "A filha rebelde" perguntamos: As mães têm preferência por filhas? Todas as mães têm preferências? E as filhas, gostam de ser preferidas? Elas se revoltam se não são? Pode-se mudar esta relação? Qual o papel do pai? Ele pode mudar alguma coisa? Todas as famílias têm problemas de relacionamento? Por quê? A comida é problema? Só tem comida para uma filha? Costuma faltar comida nas casas das famílias? Com mais comida 


\section{Urdimento}

${ }^{12}$ Gestus aqui é usado no sentido brechtiano de gesto social.

${ }^{13} \mathrm{Na}$ nossa proposta, as jovens do grupo se rodiziavam na interpretação da personagem Kelly

${ }^{14}$ Da mesma forma, muitos meninos interpretavam o Romário.

${ }^{15}$ Teatro da UBRO, no centro de Florianópolis. o problema entre a mãe e a filha continuaria? Seria o mesmo problema? O que leva uma filha a se rebelar? Qual o futuro da filha que é discriminada na família? Estas brigas se repetem todos os dias?

As polêmicas surgidas através desses questionamentos aprofundaram as cenas e o envolvimento dos adolescentes com o trabalho.

Sobre a cena "A fuga" perguntamos: Meninas sempre engravidam de meninos? Kelly sabia que poderia engravidar? Ela queria? Romário amava Kelly? Que tipo de relação existia entre os dois? Há quanto tempo já se conheciam? Onde transavam? Desde quando transavam? Eles usavam preservativos? Os dois tinham prazer? Ela "gozava"? Os pais sabiam que eles transavam? Poderiam conversar com eles sobre isto? O que diriam? A Kelly conversou com seus pais sobre o assunto? E Romário conversou? Por que ele foge? O que os amigos aconselhariam?

Os jovens iam confrontando suas contradições: ela queria ou não engravidar? A resposta foi unânime: ela não queria engravidar. Questionamos, então, mas por que transou sem camisinha? Ela sabia que podia engravidar? Propusemos então que improvisassem o momento que decidiu transar sem camisinha. As cenas ganhavam detalhes, o objetivo dos personagens ficavam mais claros e o interesse dos jovens pelo teatro aumentava.

O trabalho com os gestus $^{12}$ dos personagens foi fundamental para trazer o personagem para o corpo dos atores. Num dos jogos, propusemos que se organizassem em grupos de personagens: as Kellies ${ }^{13}$; os Romários ${ }^{14}$; os pais e mães, adultos em geral que tomavam parte nas cenas; e os traficantes. Cada hora um liderava o grupo, que imitava seus gestus e se relacionava com os outros grupos de personagens Este trabalho buscava entender o que havia de diferente e o que havia de semelhante entre os personagens.

$\mathrm{O}$ resultado foi apresentado num pequeno teatro ${ }^{15}$ e a comunidade foi convidada para assistir. Não foi uma grande audiência, mas quem veio gostou. Para os jovens, apresentar foi uma conquista, o crescimento deles era visível.

\section{Considerações Finais}

Pode-se dizer que o trabalho de Ratones foi principalmente baseado em Paulo Freire e seu conceito de codificação. Nosso conhecimento profundo sobre a comunidade ajudou a identificar as codificações com facilidade e elas puderam guiar o processo criativo. O grupo de Ratones já tinha uma familiaridade com a linguagem teatral, o que facilitou a construção das cenas. 
A resposta da comunidade de Ratones também foi mais presente. $\mathrm{O}$ trabalho de teatro já conseguiu um grande enraizamento na comunidade, que responde prontamente lotando o salão da igreja nas apresentações teatrais. Neste momento em que dois membros da comunidade assumiram a coordenação do trabalho, a resposta da comunidade foi ainda mais forte. $\mathrm{O}$ teatro passou a ser um recurso da comunidade.

Do ponto de vista do questionamento da realidade da comunidade, pode-se dizer que o teatro aumentou o debate sobre os problemas dentro e fora do grupo. Se houve uma reação negativa impedindo o grupo de se apresentar no salão da igreja, essa atitude gerou, por outro lado, um debate maior ainda entre os moradores de Ratones. Quando o grupo foi apresentar um novo espetáculo, "O Quintal Esquecido"16, teve que inicialmente se apresentar fora da comunidade, em função da proibição do uso do salão. Isso gerou uma indignação de alguns moradores que se mobilizaram e conseguiram reverter o problema. A apresentação em Ratones do novo espetáculo do grupo afirmou ainda mais o significado do teatro na comunidade.

Nosso conhecimento da comunidade Nova Esperança ainda era superficial quando iniciamos o trabalho com os jovens. Isso nos levou a uma investigação de "fragmentos de realidade" através do trabalho teatral, principalmente através da criação de imagens. Esses fragmentos também podem ser identificados como codificações, mas não de uma coisa que aconteceu na comunidade, como no caso de Ratones, mas como problemas apontados pelos jovens, que se mostravam significativos para eles.

Vale lembrar que a identificação da codificação depende dos facilitadores do trabalho. Em ambos os casos, os facilitadores participavam de reuniões semanais com a supervisora, quando discutíamos nossa leitura do grupo, tentando identificar as codificações e o encaminhamento dos trabalhos. O que se buscava era identificar as situações significativas que, segundo Freire, pudessem ser reconhecidas pelas comunidades, não podendo ser nem muito enigmática, nem muito explícita. A riqueza da codificação permite que o processo de criação do espetáculo seja rico, bem como sua recepção pela comunidade.

Havia também uma diferença entre os grupos em termos de familiaridade com a linguagem teatral. O grupo de Ratones, apesar de ter participantes novos, incluía pessoas que já faziam teatro desde os anos 90 . O grupo de Nova Esperança era tímido, desconcentrado, o processo teve que envolver a descoberta do jogo teatral, nem sempre fácil de ser conduzido.

${ }^{16}$ Espetáculo criado em 2005 pelo grupo e apresentado dentro e fora da comunidade. 


\section{Urdimento}

${ }^{17}$ Referência à leitura que Tim Prentki faz da relação entre 0 Coringa de Boal e 0 Narrador de Brecht em "Fooling with Social Intervention: Azdak, Brecht's Dialectical Jocker", apresentado na Conferência de Exeter, em 2005.

${ }^{18}$ Referência a artigo de Márcia Pompeo Nogueira na revista Urdimento No 4/2002.
Foi muito interessante, neste processo, a relação forma e conteúdo. As propostas brechtianas de trabalho com os gestus, com a droga simbólica, historicizando as cenas criadas permitiram que a linguagem teatral fosse descoberta enquanto se estranhava o cotidiano. O debate surgia da representação, os conteúdos eram apropriados no jogo teatral.

A representação sem obrigação de criar a hipnose também contribuiu para a descoberta do grupo de sua forma de representar. Saíam das cenas e logo viravam eles mesmos. Este fato podia ser interpretado como um problema, mas seguindo a orientação brechtiana, em que o ator não se confunde como o personagem, este problema virava uma solução.

Fica claro que esta estética, típica do Teatro na Comunidade, não pode ser julgada com padrões do teatro profissional. Sua riqueza singular era perceptível na linguagem do grupo em cena, incluindo suas gírias. Cada grupo expressava seu contexto, seus interesses. Assistindo o espetáculo percebíamos quem eram esses jovens, sua problemática, seu estilo de vida estavam presentes no espetáculo. Ganharam visibilidade.

Não acho que nesses trabalhos exploramos todo o potencial deste relacionamento entre Brecht e Freire. Existem muitos caminhos para se avançar neste sentido, respeitando o diálogo no processo criativo, relacionando o trabalho com a realidade, olhando para ela de forma distanciada; pensando sobre a realidade e explorando a linguagem teatral de forma lúdica. Muitos caminhos estão para serem abertos: explorando o coringa-narrador ${ }^{17}$, as codificações imaginárias ${ }^{18}$, entre outros. Em termos metodológicos, considero esta relação estimulante, com contribuições para a prática do Teatro para o Desenvolvimento de Comunidades. 


\section{Referências}

BORNHEIM, Gerd. Brecht: a Estética do Teatro. Rio de Janeiro, Graal, 1992.

BRECHT, Bertolt. Teatro Dialético. Rio de Janeiro: Civilização Brasileira, 1967.

Diário de Trabalho, Volume 1: 1938-1941. Rio de Janeiro: Rocco, 2002. Teatro Completo 3. Rio de Janeiro: Paz e Terra, 1988.

DORT, Bernard. O Teatro e sua Realidade. São Paulo: Perspectiva, 1977.

FREIRE, Paulo. Pedagogia do Oprimido. Rio de Janeiro: Paz e Terra, 1977.

Ação Cultural para a Liberdade e outros escritos. Rio de Janeiro: Paz e Terra, 1982.

JAMESON, Fredric. O Método Brecht. Petrópolis: Vozes, 1999.

NOGUEIRA, Marcia Pompeo, "Buscando uma Interação Teatral e Poética com a comunidade", Urdimento, no 04, 2002.

WRIGHT, Elizabeth, Postmodern Brecht, Londres, Routledge, 1989. 